\title{
A new beginning for The Journal of Physiological Sciences: a message from the editor-in-chief
}

\author{
Yasuo Sakuma
}

Published online: 13 December 2008

(C) The Physiological Society of Japan and Springer 2008

Since its inception in 1927, The Journal of Physiological Sciences has been a forum for the publishing of scientific results in physiology in its widest designation. In keeping with this tradition, and beginning with this issue, we have a new publisher-Springer. As a result, our journal not only gains a new scope but also allows scientists all over the world to access its contents through SpringerLink, the electronic data source operated by Springer. Papers cleared for publication through a peer-review process will appear much more quickly on the journal's Online First web link.

Many journals compete for a high impact factor; that is, it is important to them to attract as many citations as possible. $\mathrm{We}$, of course, are trying to improve the number of citations of articles published in this journal; however, we already have attained a good track record in citation longevity in terms of the cited half-life, meaning the results presented here have a long-lasting influence for posterity. It is my hope that the journal will continue to make contributions to the progress of research in physiology and toward the understanding of the "logic of life." We will be actively publishing original research results and technical notes as in the past. Papers with either experimental or conceptual approaches are welcome. Our letters-to-the-editor section will provide a forum for the discussion of controversial issues in science that are sure to benefit our readers. We will also continue to publish review articles to provide the readership with cutting-edge information on physiology. For this purpose, the journal welcomes both invited and non-invited reviews in every field of physiology.
At this time, we are introducing a new electronic editorial system, Editorial Manager, to simplify submission and shorten the time needed to review and reach decisions regarding eventual publication, and to facilitate transparency by releasing tracking records. Authors can view a manuscript's status online at any time and can respond to reviewers' comments as well as submit revisions online. As in the past, abstracts of the Annual Meeting of The Physiological Society of Japan will be published as a supplementary issue of the journal. The change of publisher is particularly appropriate at this time because the 36th International Congress of Physiological Sciences will meet in Kyoto from July 27 to August 1 of 2009, during which year the supplement will contain abstracts of the congress. Through Springer's worldwide network, physiologists around the world will be able to access the congress, whose focus will be "Function of Life: Elements and Integration."

The Physiological Society of Japan sincerely hopes to continue to contribute to the promotion of science through this upgraded version of the journal. Along with the congress, understanding the "Function of Life" will help culminate in the improvement of people's health. With these convictions in mind, I am confident that our decision to have Springer as our new publisher will further advance our journal's presence in the world's scientific arena.

Yasuo Sakuma
Y. Sakuma $(\bowtie)$

Department of Physiology, Nippon Medical School,

Tokyo 113-8602, Japan

e-mail: ysakuma@nms.ac.jp 